\title{
Complexation of aromatic drugs with single-walled carbon nanotubes
}

\author{
Anatoly S. Buchelnikov - Dmitry P. Voronin - Viktor V. Kostjukov • \\ Tatyana A. Deryabina - Sergii V. Khrapatiy • Yuriy I. Prylutskyy • \\ Uwe Ritter - Maxim P. Evstigneev
}

Received: 11 March 2014/ Accepted: 20 May 2014

(C) Springer Science+Business Media Dordrecht 2014

\begin{abstract}
We report a detailed study of the complexation of aromatic molecules and drugs with the surface of single-walled carbon nanotubes (SWCNTs, the diameter and the length ranges are 0.5-2 $\mathrm{nm}$ and 1-5 $\mu \mathrm{m}$, respectively) in terms of equilibrium binding constants, $K$. It is found that the binding constants have magnitudes of the order of $10^{4}-10^{5} \mathrm{M}^{-1}$ and that there is some ligand specificity to the SWCNT surface depending on the structure of the aromatic molecule. The observed specificity is strongly governed by the curvature of the ligand chromophore and the type of side chains, resulting in the highest $K$ for methylene blue which closely matches the curvature of the SWCNT surface. Stabilization of the drug-SWCNT
\end{abstract}

A. S. Buchelnikov · M. P. Evstigneev

Department of Biology and Chemistry, Belgorod State University, Belgorod 308015, Russia

D. P. Voronin · V. V. Kostjukov - T. A. Deryabina ·

M. P. Evstigneev ( $₫)$

Department of Physics, Sevastopol National Technical

University, 33 Universitetskaya str., Sevastopol 99053,

Ukraine

e-mail: max_evstigneev@mail.ru

S. V. Khrapatiy · Y. I. Prylutskyy

Department of Biophysics, ESC "Institute of Biology",

Taras Shevchenko National University of Kyiv,

Kiev 01601, Ukraine

U. Ritter

Institute of Chemistry and Biotechnology, Technical

University of Ilmenau, 98693 Ilmenau, Germany complexes is found to be mainly due to intermolecular van der Waals forces and to a lesser extent by hydrophobic interactions. The approach suggested for determination of the binding parameters may be used as an alternative, or complementary, to standard Langmuir analysis.

Keywords Aromatic drug - Single-walled carbon nanotube Complexation - Decomposition of Gibbs energy $\cdot \mathrm{UV} / \mathrm{Vis}$ spectroscopy $\cdot$ Atomic force microscopy

\section{Introduction}

A great deal of attention in the past decade has been given to utilizing the unique physico-chemical properties of carbon nanotubes (CNTs) in different fields of science. Applications have appeared in molecular electronics (Avouris 2002; Cao et al. 2013; Ogloblya et al. 2010), nanobiotechnology (Andreichenko et al. 2012; Ge et al. 2011; Liu et al. 2009a; Prylutska et al. 2013), biosensorics (Ogloblya et al. 2009; Panchapakesan et al. 2012; Wang et al. 2003), cancer therapy (Ali-Boucetta et al. 2008; Adeli et al. 2013; Burlaka et al. 2010; Liu et al. 2009b) etc.

The interaction of CNTs with small molecules (Tasis et al. 2006) and biopolymers, such as nucleic acids (Albertorio et al. 2009; Karachevtsev and Karachevtsev 2011; Tasis et al. 2006), is currently of 
great importance. It has been reported that the noncovalent complexation of aromatic antitumor antibiotics with CNTs may act as a regulator of their biological action (Ali-Boucetta et al. 2008; Liu et al. 2009 b) in the same way as currently known for DNAbinding aromatic drugs (Evstigneev 2010). In particular, the adsorption of drug on CNT surface results in lowering of its active concentration in solution thereby limiting its binding with bioreceptor (Ali-Boucetta et al. 2008; Liu et al. 2009b). Ligand-CNT complexes also provide a method to transfer CNTs into liquid state (Nakashima 2006; Qin et al. 2004; Shen et al. 2012), or as the means to deliver surface-adsorbed drugs to a biological receptor (Adeli et al. 2013; Assali et al. 2013; Liu et al. 2007, 2009a; Pastorin et al. 2006). Nowadays, several novel CNT-based tumortargeted drug delivery systems have been developed demonstrating ability to suppress proliferation of cancer cells, thus providing a new promising approach in antitumor therapy (Adeli et al. 2013; Chen et al. 2008). As a consequence, investigations of CNT complexation with antibiotics (Ji et al. 2009, 2010; Wang et al. 2009), dyes (Chagovets et al. 2012; Gupta et al. 2013; Koh et al. 2012; Kuo et al. 2008; Liu et al. 2008; Machado et al. 2012; Yao et al. 2010), and other types of ligands (Pan and Xing 2008; Yan et al. 2008; Yang and Xing 2010), have been undertaken with an aim to determine the binding parameters in solution.

In the all above-listed applications of CNTs, the principal mechanism of nanotube action is linked to the ability of various drugs to form complexes with CNT surface. Considering the equilibrium state of drug and CNT in solution, the strength of their complexation will eventually be determined by Gibbs free energy change (or equilibrium binding constant, $K)$. Knowledge of the binding constant is needed to categorize the binding affinity of different ligands to CNT in order to rationalize the prediction of physicochemical or biological effects of the complexation of ligand with CNT, as well as get insight into energetics of binding. Most of the experimental work on quantitation of drug-CNT complexations has so far been made using drug adsorption studies [see (Gupta et al. 2013; Kuo et al. 2008; Yang and Xing 2010) for review] which provide a simple measure of binding ability or relative stability of a complex. However, the common Langmuir (or Freundlich, Liu etc.) approach used in adsorption studies requires accurate separation of the adsorbed and non-adsorbed drug which affects the value of Langmuir-type equilibrium binding constant, $K$. Moreover, the Langmuir-type adsorption parameters may not correlate with the binding affinity due to the influence of the adsorption process on aggregated state of CNTs in solution (Koh et al. 2012), and may not fit experimental data (Yang and Xing 2010).

In the present work, we develop a simple UV/Vis spectroscopic method to estimate the equilibrium binding constants, $K$, for various typical aromatic molecules with single-walled carbon nanotubes (SWCNTs) in aqueous suspension, which does not require separation of the adsorbed and non-adsorbed drug, allows to introduce into the reaction scheme other processes, and therefore, may be used as an alternative to a standard Langmuir-type equilibrium adsorption analysis of binding.

\section{Materials and methods}

\section{Chemicals}

\section{SWCNTS}

SWCNTs were synthesized by means of the arcdischarge technique between two graphite electrodes in He atmosphere (700 mbar). The anode was drilled and filled with the catalytic powder (graphite, $1 \%$ $\mathrm{Y}_{2} \mathrm{O}_{3}, 4.2 \% \mathrm{NiO}$ ). The arc-discharge was performed with a current of $150 \mathrm{~A}$. The contaminants such as amorphous carbon and metallic catalyst particles were removed after a treatment with boiling $\mathrm{HCl}(6 \mathrm{M})$ in a reflux condenser. According to the electron microscopic micrographs [SEM and TEM data (Prylutska et al. 2013)], the diameter and the length of SWCNTs were $0.5-2 \mathrm{~nm}$ and $1-5 \mu \mathrm{m}$, respectively.

For characterization of the samples, we also employed the thermogravimetric analysis (TG, Sartorius MC5) in air. The TG showed an unburned residue (catalyst particles) at $T=1,323 \mathrm{~K}$ of less than $0.3 \%$ by mass. Additionally, characterization of SWCNTs was performed by means of X-ray photoelectron spectroscopy (data not shown) in a way previously applied for MWCNTs (Prylutska et al. 2008).

Functionalization (carboxylation) of SWCNTs was accomplished by $\mathrm{HNO}_{3}(3 \mathrm{M})$ treatment during $2 \mathrm{~h}$ at $T=373 \mathrm{~K}$ with the aim to improve their hydrophilicity. The functionalized SWCNTs were suspended in 
<smiles>COc1cccc2c1C(=O)c1c(O)c3c(c(O)c1C2=O)C[C@@](O)(C(=O)CO)C[C@@H]3O[C@H]1C[C@H]([NH3+])[C@H](O)[C@H](C)O1</smiles>

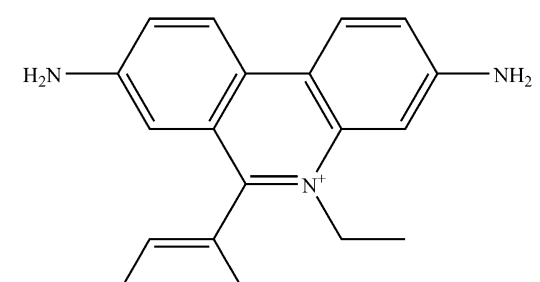

Ethidium Bromide<smiles>CN(C)c1ccc2c(c1)SC1=CC(N(C)C)C=CC1=N2</smiles><smiles>Nc1ccc2cc3ccc(N)cc3nc2c1</smiles>

Fig. 1 Chemical structures of aromatic compounds

distilled water by ultrasonication (UZDN-1 U42 (Russia); $21 \mathrm{kHz} ; 0.68 \mathrm{~A}$, processing time $90 \mathrm{~s}$ at constant heat removal) allowing dissolution of some SWCNTs in water. The obtained suspension was filtered out by means of membrane filter (pore size was $1.2 \mu \mathrm{m})$.

The concentration of SWCNTs in water was determined as the concentration of total carbon in aqueous suspension and was amounted to $5 \mu \mathrm{g} / \mathrm{ml}$ (Analytik Jena TOC Analyser multi N/C 3100).

\section{Doxorubicin (DOX)}

An initial aqueous stock solution of DOX (Ebewe, Austria) (Fig. 1) with a concentration of $2 \mathrm{mg} / \mathrm{ml}$ $\left(3.5 \times 10^{-3} \mathrm{M}\right)$ was used to obtain diluted solution $\left(8 \times 10^{-5} \mathrm{M}\right)$ by means of addition of doubly distilled water $(4.9 \mathrm{ml})$ into the stock $(0.12 \mathrm{ml})$. Titrations were performed with the solutions having half the concentration of DOX $\left(4 \times 10^{-5} \mathrm{M}\right)$.

\section{Ethidium bromide (EB)}

A solution of EB (Sigma, USA, Cat. No.: E-8751) (Fig. 1) $\left(1.4 \times 10^{-4} \mathrm{M}\right)$ was prepared by dissolving $(1.1 \mathrm{mg})$ of the compound in doubly distilled water $(19.9 \mathrm{ml})$ and titrations were performed with the solutions having half the concentration of EB $\left(7 \times 10^{-5} \mathrm{M}\right)$.

\section{Methylene blue (MB)}

A solution of MB (Sigma, USA, Cat. No.: 861243) (Fig. 1) $\left(1.4 \times 10^{-4} \mathrm{M}\right)$ was prepared by dissolving $(1.1 \mathrm{mg})$ of the compound in doubly distilled water $(21 \mathrm{ml})$. An initial solution $(0.5 \mathrm{ml})$ was used in order to obtain the solution $\left(1.4 \times 10^{-5} \mathrm{M}\right)$ by the addition of doubly distilled water $(4.5 \mathrm{ml})$ and titrations were performed with the solutions having half the concentration of MB $\left(7 \times 10^{-6} \mathrm{M}\right)$.

\section{Proflavine (PF)}

A solution of PF (Sigma, USA, Cat. No.: P-4646) (Fig. 1) $\left(2.6 \times 10^{-4} \mathrm{M}\right)$ was prepared by dissolving $(1.0 \mathrm{mg})$ the compound in doubly distilled water $(15.7 \mathrm{ml})$. An initial solution $(0.5 \mathrm{ml})$ was used in order to obtain the solution $\left(2.6 \times 10^{-5} \mathrm{M}\right)$ by addition of doubly distilled water $(4.5 \mathrm{ml})$ and titrations were performed with the solutions having half the concentration of PF $\left(1.3 \times 10^{-5} \mathrm{M}\right)$.

Measurements

\section{Atomic force microscopy (AFM)}

The state of SWCNTs in water was monitored using an AFM technique ('Solver Pro M' system; NT-MDT, Russia). The samples were deposited onto a cleaved mica substrate (V-1 Grade, SPI Supplies) by precipitation from an aqueous suspension droplet. Prior to being applied to the mica substrate, the drop of the suspension ("spot") was subjected to mechanical treatment in an ultrasonic bath for $10 \mathrm{~min}$ so that no 
suspension heterogeneity was observed. The area of the substrate covered by the spot was $\sim 1 \mathrm{~mm}^{2}$. AFM measurements were performed after evaporation of the solvent. Several sites within the 'spot' were selected. AFM visualization of the samples using a NSG10 (NT-MDT) probe was carried out in the semicontact (tapping) mode.

\section{UV/Vis spectroscopy}

Spectra were recorded using a double-beam spectrophotometer SQ-4802 (UNICO, USA) in polymethylmethacrylate cuvettes (Spain) having optical path length of $1 \mathrm{~cm}$, which enables measurements to be performed over the wavelength region $280-800 \mathrm{~nm}$. The temperature was maintained constant at $T=298 \mathrm{~K}$.

The SWCNT suspension gives a broad spectrum covering the whole UV and visible region (Remeniak et al. 2009) as a consequence, in part, of light scattering from SWCNTs. In order to exclude background scattering, all the experiments were carried out by recording spectra in the mixture of ligand and SWCNT against the suspension of pure SWCNT at the same concentration in the reference cuvette.

The measurements were performed according to the following protocol: five cuvettes were filled by SWCNTs $(0.5 \mathrm{ml}, 5 \mu \mathrm{g} / \mathrm{ml})$. After that doubly distilled water $(0.5 \mathrm{ml})$ was added into one of the cuvettes and the solution of each of the four ligands $(0.5 \mathrm{ml})$ was added into the other four cuvettes. The resultant solutions were thoroughly mixed. Hence, the starting SWCNT concentration in each pair of the cuvettes used for the measurements (one of them was always the reference cuvette and another one was a cuvette with the mixture under study) was $2.5 \mu \mathrm{g} / \mathrm{ml}$. Spectral changes were recorded in the region of wavelengths $300-750 \mathrm{~nm}$ in $0.5 \mathrm{~nm}$ steps. Titration was performed by the extraction of a certain volume of suspension out of each cuvette with further addition of the same amounts of doubly distilled water into the reference cuvette, and the ligand solution into the working cuvette. The volume of solution in each cuvette was maintained constant $(1 \mathrm{ml})$ and the ligand concentrations also remained unchanged. The reference cuvette was filled either by doubly distilled water $(1 \mathrm{ml})$, or the SWCNT suspension $(1 \mathrm{ml})$ at definite concentrations. The dependence of optical density on SWCNT concentration with the ligand concentration maintained constant was measured at single wavelength corresponding to the absorption maximum of pure ligand in the visible region of spectrum. During the time course of experiment, no changes of the ligand spectrum in the mixture with SWCNT were observed suggesting that the system under study is at equilibrium. No precipitation of SWCNT was observed during the experiments.

\section{Molecular modeling}

\section{Modeling of the complexes in aqueous suspension}

Procedures for performing structural analysis and molecular dynamics (MD) of the ligand-SWCNT complexes correspond in general to those used previously for studying of different complexes of small molecules in aqueous solution (Evstigneev et al. 2013; Kostjukov et al. 2011). Briefly, the method of structure calculations is based on the following protocol. Calculations of the spatial structures of $n: 1$ ligandSWCNT complexes were performed by the methods of molecular mechanics using X-PLOR software (Brunger 1992) (version 3.851) with the CHARMM27 force field. Modeling of the aqueous environment of the interacting molecules was performed by water molecules in the form of TIP3P, placed in a cubic box with side length of $35 \AA$ (1,423 molecules). The topology of all molecules and parameterization of their valent interactions was obtained by XPLO2D software (Kleywegt 1995) taking the mean diameter of SWCNT equal to $1.4 \mathrm{~nm}$. Quantum-mechanical calculations of partial atomic charges on the CNT and ligand atoms were performed in Gaussian03 software (Frisch et al. 2009) within the framework of DFT (B3LYP) in 6-31G* basis set by the Merz-Kollman method. MD simulations were performed in order to estimate the magnitudes of mean van der Waals energies and hydration indexes. The Verlet algorithm with 2-fs timestep and the SHAKE algorithm introducing motional restraints to all hydrogen atoms were employed at a constant temperature $T=298 \mathrm{~K}$. The total evolution time was equal to $1 \mathrm{~ns}$ which provided stable values of the mean energy of interatomic interactions, computed during the course of MD. It was previously shown that such time interval satisfactorily reproduces the mean van der Waals energies of interaction between small rigid aromatic molecules (Kostjukov et al. 2011) and with $\mathrm{C}_{60}$ fullerene (Evstigneev et al. 2013). 
Analysis of the energetics of ligand-SWCNT complexes

Analysis of the energetics of ligand-SWCNT complexes was performed according to the previously published method (Kostjukov et al. 2011), which had resulted in good agreement between theoretically calculated and experimentally measured Gibbs free energy changes for a large set of different molecular complexes, including ligand- $\mathrm{C}_{60}$ fullerene complexation (Buchelnikov et al. 2013a; Evstigneev et al. 2013). The following terms of the net Gibbs free energy of the complexation reactions were taken into consideration: van der Waals (VDW) interactions (intermolecular, $\Delta G_{\mathrm{vdW}}^{\mathrm{im}}$, and with the aqueous environment, $\Delta G_{\mathrm{vdW}}^{\mathrm{solv}}$ ), electrostatic interactions (intermolecular, $\Delta G_{\mathrm{el}}^{\mathrm{im}}$, and with the aqueous environment, $\left.\Delta G_{\mathrm{el}}^{\mathrm{solv}}\right)$, hydrophobic (HYD) interactions $\left(\Delta G_{\mathrm{hyd}}\right)$, hydrogen bonds with water molecules $\left(\Delta G_{\mathrm{HB}}\right)$, loss of translational $\left(\Delta G_{\text {tr }}\right)$ and rotational $\left(\Delta G_{\text {rot }}\right)$ degrees of freedom, formation of new vibrational modes of chemical bonds $\left(\Delta G_{\text {vibr }}^{\mathrm{I}}\right)$ and mechanical vibrations of the molecules within the complex ( $\left.\Delta G_{\mathrm{vibr}}^{\mathrm{II}}\right)$. The sum of all these terms gives the net Gibbs free energy change, $\Delta G_{\text {total }}$, in complexation reactions, which, in turn, may be derived from the experimentally measured equilibrium complexation constant, $K$, as $\Delta G_{\text {total }}=-R T \ln K$.

The computation of each of the above-listed terms was performed according to the following protocols (Evstigneev et al. 2013; Kostjukov et al. 2011). The calculation of the VDW interactions was performed by averaging the VDW part of the interaction energy during the course of MD in X-PLOR software. The energy of electrostatic interactions was calculated by solution of the non-linear Poisson-Boltzmann equation in DelPhi software (Rocchia et al. 2001). The energy of hydrophobic interactions was computed from the change in solvent accessible surface area. The energy contribution from hydrogen bonds to water molecules on complexation, $\Delta G_{\mathrm{HB}}$, was estimated from the change in hydration index of the system. Calculation of the vibrations of chemical bonds was performed by Dreiding normal mode analysis in Gaussian03 software. Calculation of mechanical vibrations of the molecules in the complex was performed by means of estimation of the rigidity factor against small translational shifts.

\section{Results and discussion}

The binding ability of a set of typical aromatic compounds (viz. DOX, EB, PF, and MB, Fig. 1) with SWCNT has been investigated. The aromatic molecules were selected using the following criteria:

(i) they all contain a planar chromophore, which is considered to be the main property enabling stacking-type complexation with the surface of SWCNT (Gupta et al. 2013; Ji et al. 2009; Koh et al. 2012; Liu et al. 2008; Pan and Xing 2008);

(ii) the binding of some of these molecules [particularly, MB and acridine orange (which is structurally similar to PF)] with SWCNTs has been characterized qualitatively in the past (Liu et al. 2008; Yan et al. 2005);

(iii) all these molecules absorb in the visible range of spectrum enabling UV/Vis spectroscopy to be used to quantify the binding;

(iv) all these drugs bear positive charge under neutral $\mathrm{pH}$ used in experiments, allowing to minimize the contribution of electrostatic factor into the difference between the magnitudes of the binding parameters of the drugs.

Determination of the equilibrium constants of ligand binding with SWCNTs in water suspension appears to be a difficult task. The principal difficulties are the very low level of solubility of SWCNTs in water and the need to know the exact state of SWCNTs in water (aggregated or non-aggregated), which determines the total number of binding sites on its surface and depends on the method of preparation of the SWCNT suspension. Hence, the quality of preparation of SWCNT suspension (see "Materials and methods" section) and its characterization is very important.

AFM characterization of the aqueous suspension of SWCNTs

AFM measurements (Fig. 2) demonstrate that the SWCNTs are predominantly in the non-coagulated state with minor fraction of agglomerated nanotubes (not shown). Single up to several dozens of SWCNTs molecules were observed in the $10 \times 10 \mu \mathrm{m}^{2}$ area of the mica substrate. The SWCNTs can be divided into two groups by size (Fig. 2): in the first group, the SWCNTs have diameters of $0.5-0.7 \mathrm{~nm}$ and lengths of 
Fig. 2 AFM image of dried aqueous suspension of SWCNT at concentration of $5 \mu \mathrm{g} / \mathrm{ml}$
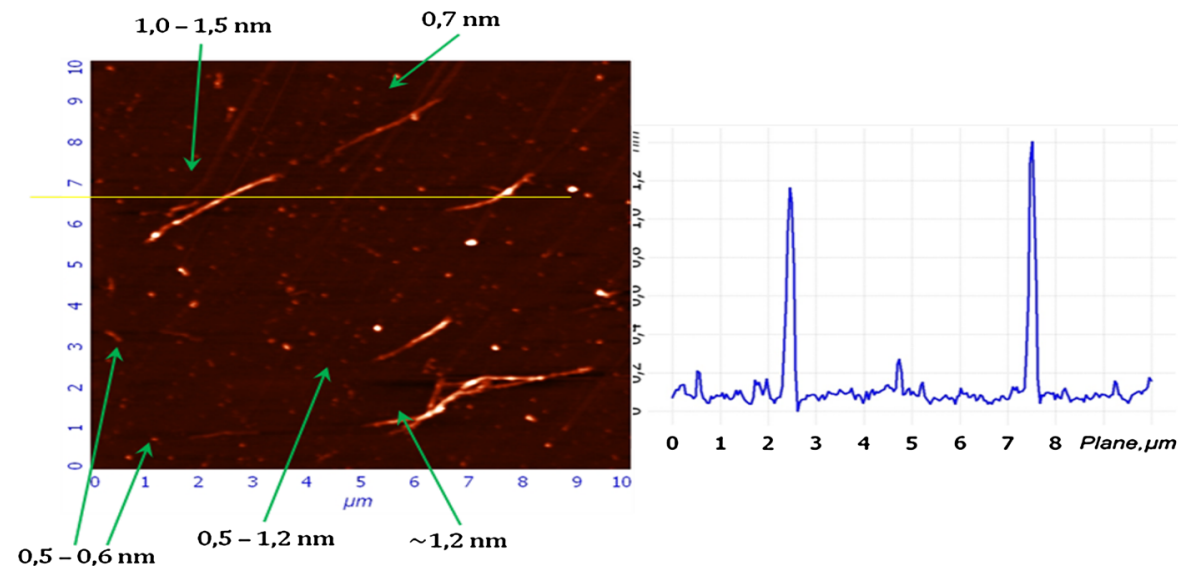

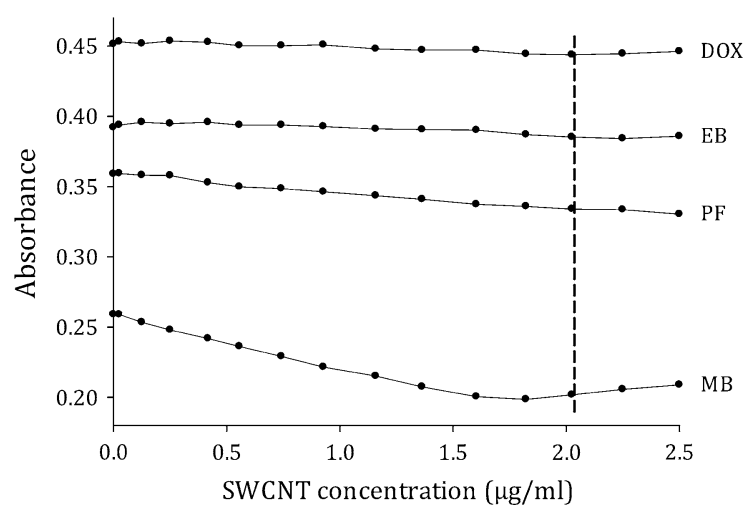

Fig. 3 Dependences of ligand absorbance on concentration of SWCNT

2-3 $\mu \mathrm{m}$, and in the second one, the SWCNTs have diameters of $1.0-1.7 \mathrm{~nm}$ and lengths of $5 \mu \mathrm{m}$ (these nanotubes are characterized by non-uniform thickness, which can reach a height of $2 \mathrm{~nm}$ ).

\section{UV/Vis study}

The results of UV/Vis titration experiments of SWCNTs with the set of aromatic ligands are shown in Fig. 3. The curves demonstrate good reproducibility, i.e. different SWCNT suspensions prepared using the same method, as described in "Materials and methods" section, give similar titration curves (data not shown).

The curves in Fig. 3 exhibit two basic features:

(i) increase in SWCNT concentration results in decrease in optical density, i.e. the hypochromic effect, which is characteristic of stacking-type complexation of planar aromatic molecules with the SWCNT surface and has previously been reported for the binding of various aromatic dyes with CNTs (Shobha Jeykumari et al. 2007; Yan et al. 2005);

(ii) three of the curves (except for PF) contain a weakly pronounced minimum at ca. $1.8 \mu \mathrm{g} / \mathrm{ml}$ of SWCNT. Although an interpretation of this behavior is outside the scope of the present work, recent studies of the complexation of $\mathrm{C}_{60}$ fullerene with the same set of aromatic drugs (Buchelnikov et al. 2013a; Evstigneev et al. 2013) reported a very similar shape for the titration curves. It was suggested that the ligands act as layers between individual fullerenes pulling them together due to compensated electrostatic repulsion and, thereby, inducing the fullerene aggregation, in a way known for saltinduced fullerene aggregation. The ligandinduced $\mathrm{C}_{60}$ fullerene aggregation is accompanied by the increased light scattering, thus leading to the increase of optical density seen at higher concentrations of the $\mathrm{C}_{60}$ molecule (Buchelnikov et al. 2013a; Evstigneev et al. 2013). On the other hand, the salt-induced aggregation due to compensated electrostatic repulsion is also well known for CNTs (Saleh et al. 2010). In addition, the porphyrin-induced aggregation of the poly $(\mathrm{rC})$-wrapped CNTs in aqueous solution has recently been reported (Zarudnev et al. 2012). All these facts indirectly point toward similarity of the origin of nonuniform titration curves in ligand- $\mathrm{C}_{60}$ and ligand-SWCNT systems, presumably 
originating from ligand-induced SWCNT aggregation, which remains to be investigated. It is suggested that points in the experimental curves at SWCNT concentration of more than $2 \mu \mathrm{g} / \mathrm{ml}$ (shown in Fig. 3 by the vertical dashed line) should be excluded in the quantitative analysis of binding, as it was done previously for the complexation of $\mathrm{C}_{60}$ fullerene with the same set of aromatic drugs (Evstigneev et al. 2013).

The most important outcome from the qualitative analysis of the titration curves in Fig. 3 is the existence of complexation of the aromatic ligands with SWCNTs in water suspension which enables a model of complexation to be built for further quantitative analysis.

The model of ligand-SWCNT complexation

AFM measurements confirm that separate SWCNTs may be considered to be the receptors of ligands in the analysis of the experimental titration curves. The hypochromic effect seen in the titration curves, as well as literature data (Chagovets et al. 2012; Cheng and Adronov 2006; Gupta et al. 2013; Ji et al. 2009; Koh et al. 2012; Nakashima 2006; Pan and Xing 2008; Rajendra et al. 2004), also support the view that the main mode of ligand binding is stacking on the surface of SWCNT. It is suggested that the minimum site for ligand binding is a portion of SWCNT surface containing $n$ carbon atoms. Knowledge of $n$ allows re-calculation of the SWCNT concentration, $N_{0}$, given in $(\mu \mathrm{g} / \mathrm{ml})$, into the concentration of the binding sites on the surface of SWCNT, $N_{\mathrm{s}}$ (mole of sites per liter) as

$N_{\mathrm{s}}=N_{0} /\left(n \cdot m_{\mathrm{C}}\right)$,

where $m_{\mathrm{C}}$ is the molar mass of carbon $(12.0107 \mathrm{~g} / \mathrm{mol})$ and $N_{\mathrm{A}}$ is the Avogadro's constant. Once the molar concentration of the binding sites is known, further introduction of equilibrium binding constant becomes possible.

The structures of the ligand-SWCNT complexes minimized by energy by means of molecular mechanics with maximal filling of the SWCNT surface by the ligand are shown in Fig. 4. Close packing of the DOX/ $\mathrm{PF} / \mathrm{EB}$ molecules on the surface was achieved when the longitudinal axes of the ligand and SWCNT were parallel, whereas for MB, they were perpendicular (a consequence of the MB chromophore being bent along the $\mathrm{N}-\mathrm{S}$ atoms so that the shape mimics the curvature of the surface of SWCNT). The obtained structure of the MB-SWCNT complex is similar to that reported (Chagovets et al. 2012). In addition, MD simulation was employed to verify the stability of such complexes by means of controlling the stability of geometry of the complex during the course of system evolution. Taking into account the length (or width) of the ligand molecule and their maximal number filling the surface, computation of the $n$ parameter is possible (see Table 1).

Let us build the simplest model to describe ligandSWCNT complexation. Let $L_{0}$ be the total molar concentration of the ligand, bound to the SWCNT surface in the non-cooperative mode; indirect justification of this assumption comes from MD simulation (Chagovets et al. 2012), which reports the random monomolecular adsorption of $\mathrm{MB}$ on the surface of CNT. In addition the fraction of agglomerated SWCNTs in solution was found to be small as evidenced from AFM measurements (see above). All this enables to consider that the ligand binding sites on SWCNT are independent of each other and to develop the model of a single SWCNT in water suspension as a mixture of small fragments, equivalent in dimension to the binding sites with concentration, $N_{\mathrm{s}}$. In fact, this approach is very similar to the classical Scatchard model for identical and independent binding sites (Scatchard 1949) used in biochemistry to describe ligand binding with biopolymers.

Let us introduce the molar concentration of unbound ligands, $L_{1}$, and unbound SWCNT sites, $N_{1}$. The ligand concentrations, $L_{0} \sim 10^{-5} \mathrm{M}$, used in experiments, are small enough to exclude any secondary ligand aggregation on the surface of SWCNT. Hence, the concentration of ligand-SWCNT complexes can be written as $K L_{1} N_{1}$, where $K$ is the equilibrium complexation constant. The mass balance equations take the form:

$\left\{\begin{array}{c}L_{1}+K N_{1} L_{1}=L_{0} \\ N_{1}+K N_{1} L_{1}=N_{\mathrm{s}}\end{array}\right.$.

It is now possible to get expression for the $N_{1}$ quantity as $N_{1}=\frac{N_{\mathrm{s}}}{1+K L_{1}}$ and derive equation for computation of the concentration of bound drug: 
Fig. 4 Structures of the ligand-SWCNT complexes minimized by energy using molecular mechanics with maximal filling of the SWCNT surface by the ligand

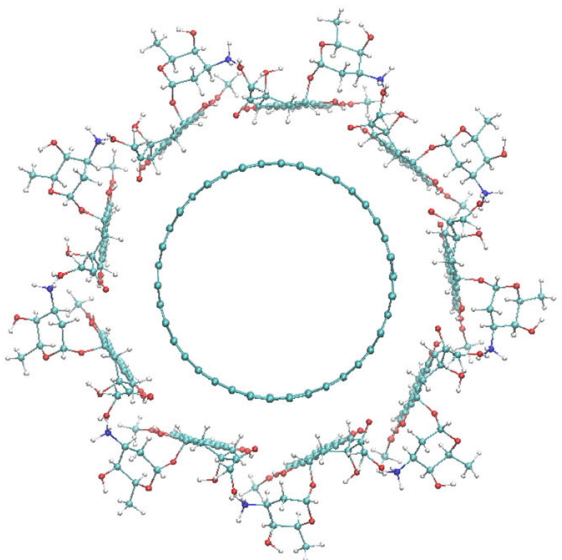

Doxorubicin

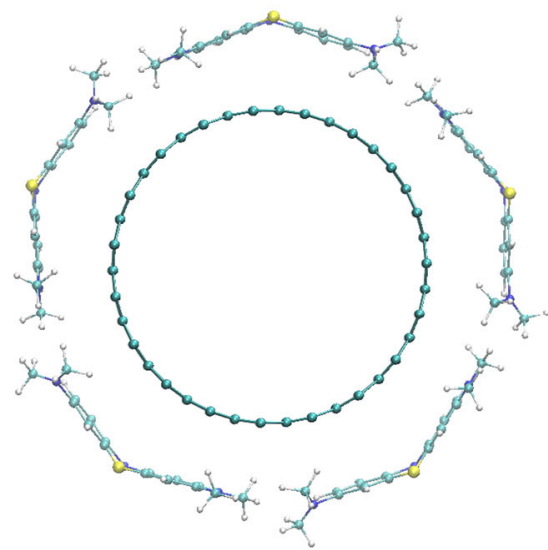

Methylene Blue

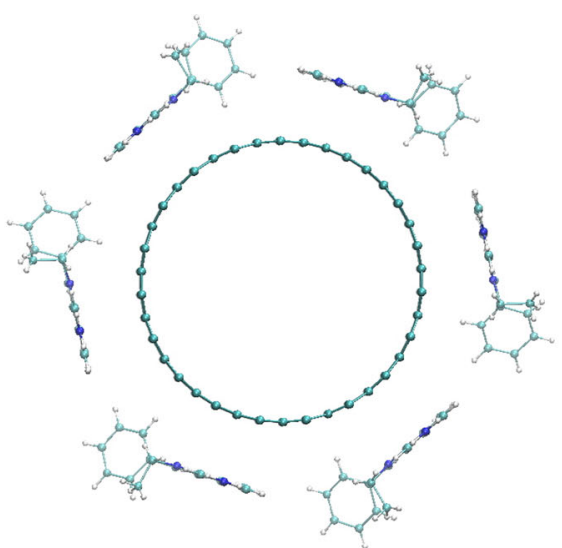

Ethidium Bromide

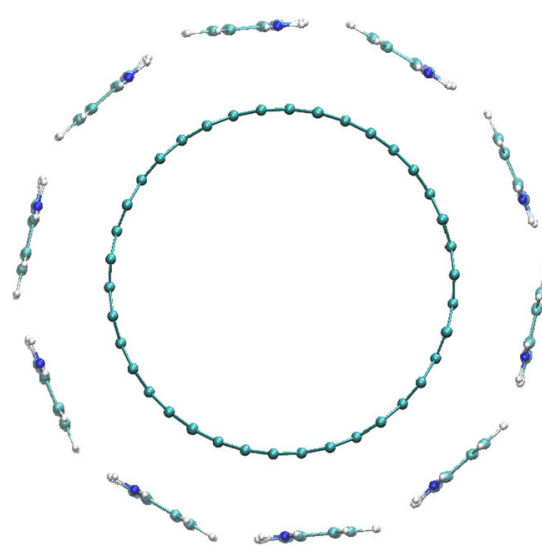

Proflavine
Table 1 Results of calculation of ligand-SWCNT binding parameters

\begin{tabular}{llrcl}
\hline Ligand & $n^{\mathrm{a}}$ & $K\left(\mathrm{M}^{-1}\right)$ & $\varepsilon_{\mathrm{c}}\left(\mathrm{M}^{-1} \mathrm{~cm}^{-1}\right)$ & $R^{2}$ \\
\hline DOX & 38 & 12,100 & $5,102.6$ & 0.935 \\
EB & 44 & 32,300 & $2,156.4$ & 0.921 \\
MB & 38 & 141,400 & $4,801.4$ & 0.990 \\
PF & 27 & 37,800 & $15,161.7$ & 0.988
\end{tabular}

${ }^{a}$ Taken from the energy-minimized structures with maximal filling by the ligand (see Fig. 4)

$K L_{1} N_{1}=\frac{K L_{1} N_{\mathrm{s}}}{1+K L_{1}}$.

Equation (3) is identical to standard Langmuir-type isotherm, $q_{\mathrm{e}}=\frac{K L_{1} q_{\mathrm{m}}}{1+K L_{1}}$, extensively used in the adsorption studies of drugs binding with nanotubes [see (Kuo et al. 2008; Machado et al. 2012; Yang and Xing 2010) and references in the "Introduction" section], where $q_{\mathrm{e}} \equiv K L_{1} N_{1}, q_{\mathrm{m}} \equiv N_{\mathrm{s}}$. It is a common practice in Langmuir approach to determine $L_{1}$ and $q_{\mathrm{e}}$ in separate experiments. However, as we shall further show, having the UV/Vis titration curve measured in experiment, this stage can be omitted. Let us derive all necessary equations in order to fully describe the UV/ Vis titration data for drug-CNT solution based on Eq. (2).

Solution of Eq. (2) with respect to the concentration of free ligand, $L_{1}$, yields

$$
L_{1}=\frac{K\left(L_{0}-N_{\mathrm{s}}\right)-1+\sqrt{\left(K\left(L_{0}-N_{\mathrm{s}}\right)-1\right)^{2}+4 K L_{0}}}{2 K} .
$$


The observed absorbance, $A$, can be expressed via the extinction coefficients of the free ligand, $\varepsilon_{\mathrm{m}}$, and its complex with SWCNT, $\varepsilon_{\mathrm{c}}$, as

$$
\begin{aligned}
A= & \varepsilon_{\mathrm{m}} L_{1}+\varepsilon_{\mathrm{c}} K L_{1} N_{1}=\varepsilon_{\mathrm{c}} L_{0}+\left(\varepsilon_{\mathrm{m}}-\varepsilon_{\mathrm{c}}\right) \\
& \frac{K\left(L_{0}-N_{\mathrm{s}}\right)-1+\sqrt{\left(K\left(L_{0}-N_{\mathrm{s}}\right)-1\right)^{2}+4 K L_{0}}}{2 K} .
\end{aligned}
$$

Substitution of Eq. (1) into Eq. (5) yields the absorption as a function of experimental concentration, $N_{0}$ :

$$
\begin{aligned}
A\left(N_{0}\right)= & \varepsilon_{\mathrm{c}} L_{0}+\frac{\varepsilon_{\mathrm{m}}-\varepsilon_{\mathrm{c}}}{2 K}\left(K\left(L_{0}-\frac{N_{0}}{n m_{\mathrm{C}}}\right)-1\right. \\
& \left.+\sqrt{\left(K\left(L_{0}-\frac{N_{0}}{n m_{\mathrm{C}}}\right)-1\right)^{2}+4 K L_{0}}\right) .
\end{aligned}
$$

Equation (6) is the main equation of the proposed model of the drug binding with the surface of SWCNT, which enables the experimental titration curves in Fig. 3 to be fitted by adjustment of the two binding parameters, $K$ and $\varepsilon_{\mathrm{c}}$. The extinction coefficients of the free ligands can be determined at infinite dilution as $\varepsilon_{\mathrm{m}}=A(0) / L_{0}$ and verified against literature data.

It is important to note that the binding model based on Eqs. (2), (6) can be further extended by means of introduction of other processes such as CNT aggregation, competitive binding of different types of ligands, etc. [(Baranovskii et al. 2006) have made an example of such analysis with respect to UV/Vis data for self- and hetero-association of aromatic molecules, resulting in equations which can be reduced to Eqs. (2), (6); (Evstigneev et al. 2013) have provided an example of analysis with respect to ligand binding with strongly aggregating $\mathrm{C}_{60}$ fullerene]. The principal difficulty here would be the knowledge of the microscopic picture of CNT aggregation required to build the model, which is out of the scope of the present paper.

\section{Computation of the ligand-SWCNT binding parameters}

The results of computation of the ligand-SWCNT binding parameters using the experimental data in Fig. 3 (with the dashed line as a cutoff) and Eq. (6) are given in Table 1 . The quality of data fitting $\left(R^{2}\right)$ is good enough to state that the experimental data are well described by the model.

Prior to analyzing the results in Table 1, the issue regarding the reliability of the ligand-SWCNT binding parameters is worth considering. The basic difficulty in quantitative description of ligandSWCNT complexation is the need to know the exact concentration and the state of SWCNT in the initial aqueous suspension. Both factors depend on the method of solubilization of SWCNTs and, hence, may lead to some error in the magnitude of $K$. Even though the AFM characterization (see above) has indicated predominantly a non-coagulated state of SWCNTs in aqueous suspension, and the titration curves have demonstrated good reproducibility, there will be some error in the magnitude of SWCNTs concentration, $N_{0}$, estimation. In particular, the magnitude of $N_{0}$ may be influenced to small extent by the addition of a ligand into solution resulting in increase of SWCNT solubility (Nakashima 2006), which is difficult to account for quantitatively. In addition, the estimated dimensions of the binding sites, $n$, are approximate, which also contributes to the error in determination of $K$.

In order to find out whether the magnitudes of $K$ in Table 1 are reliable and could be used for comparative analysis, a $20 \%$ variation in the parameters, $N_{0}$ and $n$, in Eq. (6) was introduced and the full fitting procedure of the experimental curves was repeated. Although it was found that the $K$ values had now featured ca. $30 \%$ shift with respect to their values given in Table 1 , the sequence in the $K$ values remained unchanged in all possible combinations of the input parameters. The relative insensitivity of the binding equations with respect to component concentrations has also been recently noted with respect to three-component ligand 1-ligand 2-DNA systems (Buchelnikov et al. 2013b). It follows that the relative magnitudes of the binding constants may be treated as reliable, if the method of SWCNT solubilization was identical for the set of ligands studied (as in the present work). Great caution, however, should be given to any comparison of $K$ values derived from titration experiments in SWCNT suspensions prepared by different methods.

It is seen from Table 1 that the equilibrium binding constants have an order of magnitude $10^{4}-10^{5} \mathrm{M}^{-1}$, which is in agreement with the order of magnitude of Langmuir equilibrium constants obtained from adsorption studies of various aromatic dyes with 
SWCNT (Kuo et al. 2008; Machado et al. 2012). It is also worth noting that the obtained magnitudes of binding affinities with nanotubes well agree with the $K$ values for the binding of the same ligands with $\mathrm{C}_{60}$ fullerene (Evstigneev et al. 2013), having a similarly curved carbon surface as that for SWCNT. The $K$ values for the ligand-SWCNT complexation are, on average, higher than those found for the ligand- $\mathrm{C}_{60}$ fullerene complexation (Evstigneev et al. 2013). The apparent peculiarity of binding with SWCNT is that the magnitude of $K$ for MB is by an order of magnitude higher than that for the other ligands studied, whereas in the ligand $-\mathrm{C}_{60}$ fullerene systems (Evstigneev et al. 2013) the pattern was reversed, viz. the binding of DOX to fullerene was characterized by the highest $K$ and the binding of $\mathrm{MB}$ was the weakest. It was shown that the DOX molecule in complex with $\mathrm{C}_{60}$ fullerene can mold to the convex shape of the $\mathrm{C}_{60}$ molecule due to the aminosugar linked to its chromophore (see Fig. 1), providing the most favorable hydrophobic and van der Waals contact. In case of a linear SWCNT, the bulky chains attached to the ligand chromophore likely create steric hindrance for tight binding. In case of MB-SWCNT complexation, the shape of the MB chromophore, bent along the N-S atoms in its center (see Fig. 1), presumably, is the key factor responsible for the relatively high magnitude of $K$. It is likely that such structural specificity of binding may be observed only in cases when the CNT diameter commensurate with the drugs' dimensions (as is the case in the present work, i.e., $d_{\mathrm{CNT}} \sim 1 \ldots 2 \mathrm{~nm}$ ). This conclusion is supported by recently reported diameterdependent DOX binding with SWCNT (Liu et al. 2007). Contrary to that it was previously shown that the drugs' binding with multi-walled CNTs having much larger dimensions, $d_{\mathrm{CNT}} \sim 20 \ldots 30 \mathrm{~nm}$, is characterized by greater adsorption capacity with respect to planar molecules and lesser capacity with respect to non-planar ones (Liu et al. 2008), i.e., no real structural specificity was observed.

The importance of structural factor in drugs' binding with SWCNT revealed in the present work significantly extends the current knowledge on specificity of such complexation, which is mainly grounded on the simple view that the adsorption capacity is increased with an increase in drug's surface area (Carabineiro et al. 2012).

Further insight into the nature of physical factors stabilizing the ligand-SWCNT complexes was obtained from analysis of the energies involved in the binding process.

\section{Energetics of ligand-SWCNT complexation}

The calculated values of the terms of the net Gibbs free energy, related to the contribution of various physical factors to the energetics of ligand-SWCNT complexation, are summarized in Table 2. Typical error in the computation of each term in Table 2 using the methods of MD and force fields for the molecules of this type is about $1-2 \mathrm{kcal} / \mathrm{mol}$ [see discussion of the sources of errors (Kostjukov et al. 2011)], hence, the net energy, $\Delta G_{\text {total }}$, formed as the sum of all terms, will always give an apparently larger error. The agreement between the theoretically computed sum of the energy terms, $\Delta G_{\text {total }}$, and the experimental energy of complexation, $\Delta G_{\text {exp }}$, for $\mathrm{DOX}, \mathrm{EB}$, and $\mathrm{PF}$ may be considered as good enough, whereas the results for MB are worse. Nevertheless, the results in Table 2 provide a qualitative understanding of the relative contributions of various factors to the stabilization of the ligand-SWCNT complexes.

The main factors contributing to stabilization of the ligand-SWCNT complexes are intermolecular VDW interactions and, to a lesser extent, hydrophobic interactions and formation of new mechanical vibrations of the ligand within the complex, $\Delta G_{\text {vibr }}^{\mathrm{II}}$. The importance of intermolecular VDW interactions is expected and agrees with current understanding of the energetics of binding of small molecules with carbon nanoparticles (Boyd and Reed 2004; Pan and Xing 2008). The relative distribution of the energy terms in Table 2 is very similar to that previously reported for ligand- $\mathrm{C}_{60}$ fullerene complexation (Evstigneev et al. 2013). However, the average magnitudes of either VDW or HYD energies appear to be much higher by absolute value than that reported previously for ligand- $\mathrm{C}_{60}$ fullerene complexation (Evstigneev et al. 2013). This factor explains the higher magnitudes of $K$ for the ligand-SWCNT complexation compared to those for the ligand- $\mathrm{C}_{60}$ fullerene systems.

It is seen from Table 2 that the contribution of the electrostatic factor to the net energy of complexation is very small, which is due to the neutral charge for the SWCNT surface used in the calculations. It is worth noting that even the existence of charge on the carbon surface will likely lead to a small net effect for the 
Table 2 Calculated Gibbs free energies $(\mathrm{kcal} / \mathrm{mol})$ for the complexation reactions of aromatic molecules with SWCNT

\begin{tabular}{|c|c|c|c|c|c|c|c|c|c|c|c|c|}
\hline \multirow[t]{2}{*}{ Ligand } & \multicolumn{2}{|c|}{ Van der Waals interactions } & \multicolumn{2}{|c|}{ Electrostatic interactions } & \multirow[t]{2}{*}{$\Delta G_{\text {hyd }}$} & \multirow[t]{2}{*}{$\Delta G_{\mathrm{HB}}$} & \multicolumn{4}{|c|}{ Entropic factors } & \multirow[t]{2}{*}{$\Delta G_{\text {total }}$} & \multirow[t]{2}{*}{$\Delta G_{\exp }$} \\
\hline & $\Delta G_{\mathrm{vdW}}^{\mathrm{im}}$ & $\Delta G_{\mathrm{vdW}}^{\mathrm{solv}}$ & $\Delta G_{\mathrm{el}}^{\mathrm{im}}$ & $\Delta G_{\mathrm{el}}^{\mathrm{solv}}$ & & & $\Delta G_{\mathrm{tr}}$ & $\Delta G_{\text {rot }}$ & $\Delta G_{\mathrm{vibr}}^{\mathrm{I}}$ & $\Delta G_{\mathrm{vibr}}^{\mathrm{II}}$ & & \\
\hline DOX & -45.3 & 49.3 & -0.01 & 0.9 & -18.5 & 2.4 & 12.3 & 10.3 & -6.4 & -11.2 & -6.1 & -5.6 \\
\hline EB & -33.8 & 30.6 & 0.8 & -0.01 & -16.1 & 1.3 & 11.9 & 9.5 & -2.9 & -10.4 & -9.2 & -6.1 \\
\hline MB & -32.9 & 27.8 & 1.4 & -0.04 & -19.7 & 0.2 & 11.8 & 9.2 & -2.2 & -10.2 & -14.6 & -7.0 \\
\hline PF & -27.1 & 24.8 & -0.1 & 0.9 & -13.7 & 1.4 & 11.6 & 8.7 & -2.6 & -10.8 & -6.9 & -6.2 \\
\hline
\end{tabular}

electrostatic energy due to the compensation of the formation of favorable electrostatic contact within a complex by a loss of electrostatic contact with the aqueous environment. Such effect has recently been demonstrated for the binding of charged ligands with neutral or negatively charged surface of $\mathrm{C}_{60}$ molecule (Evstigneev et al. 2013). The lowering of electrostatic energies in water was also reported in MD simulation of MB binding with CNT (Chagovets et al. 2012). The compensatory nature of the intermolecular and to water interactions for the case of ligand-SWCNT complexation is most clearly seen in Table 2 with respect to the components of the VDW energy, viz. $\Delta G_{\mathrm{vdW}}^{\mathrm{im}}$ and $\Delta G_{\mathrm{vdW}}^{\mathrm{solv}}$. Taken as a whole, similar patterns in electrostatic and VDW energies have been previously reported for ligand-ligand (Kostjukov et al. 2011) and ligand- $\mathrm{C}_{60}$ fullerene (Evstigneev et al. 2013) complexations in aqueous solutions, suggesting some similarity of interplay between the key terms of the net Gibbs free energy on aromatic ligand binding with aromatic carbon surface.

The highest by absolute value magnitude of intermolecular VDW interaction $\left(\Delta G_{\mathrm{vdW}}^{\mathrm{im}}\right)$ is obtained for the antibiotic DOX, which is quite expected taking into account the highest overlap area for this molecule with the SWCNT surface (DOX molecule contains four rings in the structure of its chromophore compared to the three rings for $\mathrm{PF}, \mathrm{EB}$, and $\mathrm{MB}$, see Fig. 1). On the other hand, the highest HYD energy is noted for $\mathrm{MB}$, which is also quite natural recalling that the MB chromophore is bent and well matches the shape of the SWCNT surface (see Fig. 4).

The activation energy for complexation of the aromatic ligands with SWCNT surface is determined by the entropic factor, giving a barrier of $\Delta G_{\mathrm{tr}}+\Delta G_{\mathrm{rot}}+\Delta G_{\mathrm{vibr}}^{\mathrm{I}}+\Delta G_{\mathrm{vibr}}^{\mathrm{II}}=5 \ldots 9 \mathrm{kcal} / \mathrm{mol}$.

This value falls within the typical range of estimated activation energies for physisorption process of direct dyes onto CNTs (Kuo et al. 2008). The entropic factor is mainly governed by the loss of translational $\left(\Delta G_{\mathrm{tr}}\right)$ and rotational $\left(\Delta G_{\text {rot }}\right)$ degrees of freedom on formation of the complex, which is slightly greater than the counterbalancing effect of the energetically favorable formation of new high- $\left(\Delta G_{\mathrm{vibr}}^{\mathrm{I}}\right)$ and low-frequency $\left(\Delta G_{\mathrm{vibr}}^{\mathrm{II}}\right.$ ) modes of vibrations (Table 2 ).

Noteworthy, the contribution of various physical factors to the net free energy of complexation discussed above reveals just the overall energy balance and interrelation of various energy contributions, but does not provide an answer to another question "What physical factors most strongly affect the binding affinity in aqueous solution?." For example, the reported above compensatory nature of electrostatic forces on drugs' binding with SWCNT does not mean that this type of interaction is not important on binding. Moreover, drug adsorption studies have shown that the adsorption capacity on CNT exerts some correlation with the charge of the drug (Liu et al. 2008) and ionic strength (Ji et al. 2010; Kuo et al. 2008). It was recently established (Kostjukov et al. 2011, 2012) that for the non-covalent binding reactions in aqueous media, the net energies (such as $\Delta G_{\mathrm{vdW}}$ or $\Delta G_{\mathrm{el}}$ ) are meaningless in terms of addressing the above-formulated question. The search of such correlation with the component energies (such as $\Delta G_{\mathrm{vdW}}^{\mathrm{im}}$ or $\Delta G_{\mathrm{el}}^{\mathrm{solv}}$ ) may answer this question correctly, which requires special selection of the set of drugs for the study and, thereby, creates a challenge for future investigations in this area.

\section{Conclusions}

In the present work, we have developed a method for the quantitative analysis of equilibrium complexation of aromatic molecules with the surface of SWCNTs in 
terms of the equilibrium binding constant $K$. It has been shown that the proposed approach can be reduced to Langmuir-type adsorption equation, currently extensively used to study drug-CNT complexations. However, in contrast to the Langmuir approach, it does not require separate measurements of the free and bound drug concentrations, and afford direct determination of the binding parameters from fitting of the UV/Vis titration curve. The equations of the proposed model allow incorporating any additional processes, such as CNT aggregation or competitive drug binding, which fall out of the scope of standard Langmuir analysis. In general, the suggested approach may be used as an alternative, or complementary to standard Langmuir analysis.

Based on the suggested approach, we estimated the magnitudes of $K$ values for four typical aromatic ligands; doxorubicin (DOX), ethidium bromide (EB), methylene blue (MB) and proflavine (PF). Knowledge of the magnitudes of the binding constants, $K$, may be used to correlate their values with the physicochemical or biological effect under study induced by complexation of the ligand with SWCNT, and to get insight into energetics of binding. In particular, the ability to categorize various drugs by their affinity to SWCNT may be important in construction of novel CNT-based tumor-targeted drug delivery systems, which are currently considered to be a promising approach in antitumor therapy (Adeli et al. 2013). It was, however, shown in the present paper that a comparative analysis of the equilibrium constants for different ligands is only reliable if the method of preparation of SWCNT suspension is the same for all the ligands involved in the study. In such cases any error in estimation of the concentration of SWCNTs and in the magnitude of other input parameters in the binding model will not affect the estimation of the relative values of the binding constants.

It was found that the calculated values of the binding constants have an order of magnitude of $10^{4}-$ $10^{5} \mathrm{M}^{-1}$ and the aromatic ligands studied exert a clear specificity to the SWCNT surface, viz. the binding constants of MB and DOX are different by an order of magnitude in their $K$ values (the higher being for MB). The observed specificity in the case of MB is governed by the curvature of the ligand chromophore, which closely matches the curvature of the SWCNT surface, whereas the bulky aminosugar of DOX appears to hinder the complex formation. The importance of structural factor in aromatic drugs' binding with SWCNTs revealed in the present work significantly extends the current knowledge on specificity of such complexation, which is mainly grounded on the simple view that the adsorption capacity is increased with increase in drug's surface area.

Stabilization of the ligand-SWCNT complexes was found to be mainly due to intermolecular van der Waals and hydrophobic interactions, the former giving the larger contribution. The net contribution from electrostatic forces is negligible due to compensation of the formation of favorable electrostatic contact within a complex by a partial loss of electrostatic contact with the aqueous environment.

Acknowledgments Professor David B. Davies (Birkbeck College, University of London) is thanked for valuable comments on the manuscript. This work was financially supported by the Russian Scientific Foundation, grant No. 14-14-00328.

\section{References}

Adeli M, Soleyman R, Beiranvand Z, Madani F (2013) Carbon nanotubes in cancer therapy: a more precise look at the role of carbon nanotube-polymer interactions. Chem Soc Rev 42(12):5231-5256. doi:10.1039/c3cs35431h

Albertorio F, Hughes ME, Golovchenko JA, Branton D (2009) Base dependent DNA-carbon nanotube interactions: activation enthalpies and assembly-disassembly control. Nanotechnology 20(39):395101. doi:10.1088/0957-4484/ 20/39/395101

Ali-Boucetta H, Al-Jamal KT, McCarthy D, Prato M, Bianco A, Kostarelos K (2008) Multiwalled carbon nanotube-doxorubicin supramolecular complexes for cancer therapeutics. Chem Commun 4:459-461. doi:10.1039/B712350G

Andreichenko K, Prylutska S, Medynska K, Bogutska K, Nurishchenko N, Prylutskyy Yu, Ritter U, Scharff P (2012) Impact of carbon nanotubes on ATPase activity and superprecipitation reaction of natural actomyosin. Int $\mathbf{J}$ Physiol Pathophysiol 3(4):341-347. doi:10.1615/ IntJPhysPathophys.v3.i4.50

Assali M, Cid J-J, Pernía-Leal M, Muñoz-Bravo M, Fernández I, Wellinger RE, Khiar N (2013) Glyconanosomes: diskshaped nanomaterials for the water solubilization and delivery of hydrophobic molecules. ACS Nano 7(3):2145-2153. doi:10.1021/nn304986x

Avouris P (2002) Molecular electronics with carbon nanotubes. Acc Chem Res 35(12):1026-1034. doi:10.1021/ar010152e

Baranovskii SF, Bolotin PA, Evstigneev MP (2006) Aggregation of 1,3,7-trimethylxanthine with methylene blue in aqueous solution. J Appl Spectrosc 73(2):171-177. doi:10. 1007/s10812-006-0054-8

Boyd PDW, Reed CA (2004) Fullerene-porphyrin constructs. Acc Chem Res 38(4):235-242. doi:10.1021/ar040168f 
Brunger AT (1992) X-PLOR: a system for X-ray crystallography and NMR. Yale University Press, Yale

Buchelnikov AS, Kostyukov VV, Yevstigneev MP, Prylutskyy YuI (2013a) Mechanism of complexation of the phenothiazine dye methylene blue with fullerene $\mathrm{C}_{60}$. Russ $\mathrm{J}$ Phys Chem A 87(4):662-667. doi:10.1134/s00360244130 40067

Buchelnikov AS, Evstigneev VP, Rodríguez Oropeza LE, Evstigneev MP (2013b) On the reliability of quantitation of biological effect in drug-interceptor-DNA systems. Eur Biophys J 42(4):315-319. doi:10.1007/s00249-013-08931

Burlaka A, Lukin S, Prylutska S, Remeniak O, Prylutskyy Yu (2010) Hyperthermic effect of multi-walled carbon nanotubes stimulated with near infrared irradiation for anticancer therapy: in vitro studies. Exp Oncol 32(1):48-50

Cao Q, Han S-J, Tulevski GS, Zhu Y, Lu DD, Haensch W (2013) Arrays of single-walled carbon nanotubes with full surface coverage for high-performance electronics. Nat Nano 8(3):180-186. doi:10.1038/nnano.2012.257

Carabineiro SAC, Thavorn-amornsri T, Pereira MFR, Serp P, Figueiredo JL (2012) Comparison between activated carbon, carbon xerogel and carbon nanotubes for the adsorption of the antibiotic ciprofloxacin. Catal Today 186(1):29-34. doi:10.1016/j.cattod.2011.08.020

Chagovets VV, Kosevich MV, Stepanian SG, Boryak OA, Shelkovsky VS, Orlov VV, Leontiev VS, Pokrovskiy VA, Adamowicz L, Karachevtsev VA (2012) Noncovalent interaction of methylene blue with carbon nanotubes: theoretical and mass spectrometry characterization. J Phys Chem C 116(38):20579-20590. doi:10.1021/jp306333c

Chen J, Chen S, Zhao X, Kuznetsova LV, Wong SS, Ojima I (2008) Functionalized single-walled carbon nanotubes as rationally designed vehicles for tumor-targeted drug delivery. J Am Chem Soc 130(49):16778-16785. doi:10. 1021/ja805570f

Cheng F, Adronov A (2006) Noncovalent functionalization and solubilization of carbon nanotubes by using a conjugated Zn-porphyrin polymer. Chem Eur J 12(19):5053-5059. doi:10.1002/chem.200600302

Evstigneev MP (2010) DNA-binding aromatic drug molecules: physico-chemical interactions and their biological roles. Lambert Academic Publishing, Saasbrücken

Evstigneev MP, Buchelnikov AS, Voronin DP, Rubin YuV, Belous LF, Prylutskyy YuI, Ritter U (2013) Complexation of $\mathrm{C}_{60}$ fullerene with aromatic drugs. ChemPhysChem 14(3):568-578. doi:10.1002/cphc.201200938

Frisch MJ, Trucks GW, Schlegel HB, Scuseria GE, Robb MA, Cheeseman JR, Montgomery JA Jr, Vreven T, Kudin KN, Burant JC, Millam JM, Iyengar SS, Tomasi J, Barone V, Mennucci B, Cossi M, Scalmani G, Rega N, Petersson GA, Nakatsuji H, Hada M, Ehara M, Toyota K, Fukuda R, Hasegawa J, Ishida M, Nakajima T, Honda Y, Kitao O, Nakai H, Klene M, Li X, Knox JE, Hratchian HP, Cross JB, Bakken V, Adamo C, Jaramillo J, Gomperts R, Stratmann RE, Yazyev O, Austin AJ, Cammi R, Pomelli C, Ochterski JW, Ayala PY, Morokuma K, Voth GA, Salvador P, Dannenberg JJ, Zakrzewski VG, Dapprich S, Daniels AD, Strain MC, Farkas O, Malick DK, Rabuck AD, Raghavachari K, Foresman JB, Ortiz JV, Cui Q, Baboul AG, Clifford S, Cioslowski J, Stefanov BB, Liu G, Liashenko A,
Piskorz P, Komaromi I, Martin RL, Fox DJ, Keith T, AlLaham MA, Peng CY, Nanayakkara A, Challacombe M, Gill PMW, Johnson B, Chen W, Wong MW, Gonzalez C, Pople JA (2009) Gaussian 09 (Revision B.01). Gaussian, Inc., Wallingford

Ge C, Du J, Zhao L, Wang L, Liu Y, Li D, Yang Y, Zhou R, Zhao Y, Chai Z, Chen C (2011) Binding of blood proteins to carbon nanotubes reduces cytotoxicity. Proc Natl Acad Sci USA 108(41):16968-16973. doi:10.1073/pnas.11052 70108

Gupta VK, Kumar R, Nayak A, Saleh TA, Barakat MA (2013) Adsorptive removal of dyes from aqueous solution onto carbon nanotubes: a review. Adv Colloid Interface Sci 193-194:24-34. doi:10.1016/j.cis.2013.03.003

Ji L, Chen W, Duan L, Zhu D (2009) Mechanisms for strong adsorption of tetracycline to carbon nanotubes: a comparative study using activated carbon and graphite as adsorbents. Environ Sci Technol 43(7):2322-2327. doi:10.1021/ es $803268 b$

Ji L, Chen W, Bi J, Zheng S, Xu Z, Zhu D, Alvarez PJ (2010) Adsorption of tetracycline on single-walled and multiwalled carbon nanotubes as affected by aqueous solution chemistry. Environ Toxicol Chem 29(12):2713-2719. doi:10.1002/etc. 350

Karachevtsev MV, Karachevtsev VA (2011) Peculiarities of homooligonucleotides wrapping around carbon nanotubes: molecular dynamics modeling. J Phys Chem B 115(29): 9271-9279. doi:10.1021/jp2026362

Kleywegt GJ (1995) Dictionaries for heteros. In: Bailey S, Wilson KS (eds) ESF/CCP4 Newsletters. Daresbury Laboratory, Warrington

Koh B, Kim G, Yoon HK, Park JB, Kopelman R, Cheng W (2012) Fluorophore and dye-assisted dispersion of carbon nanotubes in aqueous solution. Langmuir 28(32):11676-11686. doi:10. 1021/la302004p

Kostjukov VV, Khomytova NM, Hernandez Santiago AA, Cervantes Tavera A-M, Salas Alvarado J, Evstigneev MP (2011) Parsing of the free energy of aromatic-aromatic stacking interactions in solution. J Chem Thermodyn 43(10):1424-1434. doi:10.1016/j.jct.2011.04.014

Kostjukov VV, Hernandez Santiago AA, Rodriguez FR, Castilla SR, Parkinson JA, Evstigneev MP (2012) Energetics of ligand binding to the DNA minor groove. Phys Chem Chem Phys 14(16):5588-5600. doi:10.1039/C2CP40182G

Kuo C-Y, Wu C-H, Wu J-Y (2008) Adsorption of direct dyes from aqueous solutions by carbon nanotubes: determination of equilibrium, kinetics and thermodynamics parameters. J Colloid Interface Sci 327(2):308-315. doi:10.1016/ j.jcis.2008.08.038

Liu Z, Sun X, Nakayama-Ratchford N, Dai H (2007) Supramolecular chemistry on water-soluble carbon nanotubes for drug loading and delivery. ACS Nano 1(1):50-56. doi: $10.1021 / \mathrm{nn} 700040 \mathrm{t}$

Liu C-H, Li J-J, Zhang H-L, Li B-R, Guo Y (2008) Structure dependent interaction between organic dyes and carbon nanotubes. Colloids Surf A 313-314:9-12. doi:10.1016/j. colsurfa.2007.04.062

Liu Q, Chen B, Wang Q, Shi X, Xiao Z, Lin J, Fang X (2009a) Carbon nanotubes as molecular transporters for walled plant cells. Nano Lett 9(3):1007-1010. doi:10.1021/ nl803083u 
Liu Z, Fan AC, Rakhra K, Sherlock S, Goodwin A, Chen X, Yang Q, Felsher DW, Dai H (2009b) Supramolecular stacking of doxorubicin on carbon nanotubes for in vivo cancer therapy. Angew Chem Int Ed 48(41):7668-7672. doi:10.1002/anie.200902612

Machado FM, Bergmann CP, Lima EC, Royer B, de Souza FE, Jauris IM, Calvete T, Fagan SB (2012) Adsorption of reactive blue 4 dye from water solutions by carbon nanotubes: experiment and theory. Phys Chem Chem Phys 14(31):11139-11153. doi:10.1039/C2CP41475A

Nakashima N (2006) Solubilization of single-walled carbon nanotubes with condensed aromatic compounds. Sci Technol Adv Mater 7(7):609-616. doi:10.1016/j.stam. 2006.08.004

Ogloblya OV, Strzhemechny YM, Kuznetsova GM, Prylutskyy YuI, Billups WE (2009) Linear polarizability of carbon nanotubes bonded to maleimide derivative and fluorescent probe Nile red. Comput Mater Sci 46(1):112-114. doi:10. 1016/j.commatsci.2009.02.010

Ogloblya OV, Prylutskyy YuI, Strzhemechny YM (2010) Peculiarities of conductance of carbon nanotube-based quantum dots. Int J Quantum Chem 110(1):195-201. doi:10.1002/qua.22153

Pan B, Xing B (2008) Adsorption mechanisms of organic chemicals on carbon nanotubes. Environ Sci Technol 42(24):9005-9013. doi:10.1021/es801777n

Panchapakesan B, Burkhead T, King B, Xu P, Loomis J, Wickstrom E (2012) Diagnostic and therapeutic applications of carbon nanotubes. In: Irudayaraj JM (ed) Biomedical nanosensors. Pan Stanford Publishing, Stanford, pp 121-151

Pastorin G, Wu W, Wieckowski S, Briand J-P, Kostarelos K, Prato M, Bianco A (2006) Double functionalisation of carbon nanotubes for multimodal drug delivery. Chem Commun 11:1182-1184. doi:10.1039/B516309A

Prylutska SV, Grynyuk II, Matyshevska OP, Yashchuk VM, Prylutskyy YuI, Ritter U, Scharff P (2008) Estimation of multi-walled carbon nanotubes toxicity in vitro. Physica $E$ 40(7):2565-2569. doi:10.1016/j.physe.2007.07.017

Prylutska S, Bilyy R, Shkandina T, Rotko D, Bychko A, Cherepanov V, Stoika R, Rybalchenko V, Prylutskyy Yu, Tsierkezos N, Ritter U (2013) Comparative study of membranotropic action of single- and multi-walled carbon nanotubes. J Biosci Bioeng 115(6):674-679. doi:10.1016/j. jbiosc.2012.12.016

Qin S, Qin D, Ford WT, Herrera JE, Resasco DE, Bachilo SM, Weisman RB (2004) Solubilization and purification of single-wall carbon nanotubes in water by in situ radical polymerization of sodium 4-styrenesulfonate. Macromolecules 37(11):3965-3967. doi:10.1021/ma049681z

Rajendra J, Baxendale M, Dit Rap LG, Rodger A (2004) Flow linear dichroism to probe binding of aromatic molecules and DNA to single-walled carbon nanotubes. J Am Chem Soc 126(36):11182-11188. doi:10.1021/ja048720j
Remeniak OV, Prylutska SV, Bychko AV, Prylutskyy YuI, Rybalchenko VK (2009) The membranotropic action of carbon nanotubes. Rep Natl Acad Sci Ukr 2:163-167

Rocchia W, Alexov E, Honig B (2001) Extending the applicability of the nonlinear Poisson-Boltzmann equation: multiple dielectric constants and multivalent ions. J Phys Chem B 105(28):6507-6514. doi:10.1021/jp010454y

Saleh NB, Pfefferle LD, Elimelech M (2010) Influence of biomacromolecules and humic acid on the aggregation kinetics of single-walled carbon nanotubes. Environ Sci Technol 44(7):2412-2418. doi:10.1021/es903059t

Scatchard G (1949) The attractions of proteins for small molecules and ions. Ann N Y Acad Sci 51(4):660-672. doi:10. 1111/j.1749-6632.1949.tb27297.x

Shen C, Ma D, Meany B, Isaacs L, Wang Y (2012) Acyclic cucurbit[n]uril molecular containers selectively solubilize single-walled carbon nanotubes in water. J Am Chem Soc 134(17):7254-7257. doi:10.1021/ja301462e

Shobha Jeykumari DR, Ramaprabhu S, Sriman Narayanan S (2007) A thionine functionalized multiwalled carbon nanotube modified electrode for the determination of hydrogen peroxide. Carbon 45(6):1340-1353. doi:10. 1016/j.carbon.2007.01.006

Tasis D, Tagmatarchis N, Bianco A, Prato M (2006) Chemistry of carbon nanotubes. Chem Rev 106(3):1105-1136. doi: $10.1021 / \mathrm{cr} 050569$ o

Wang J, Musameh M, Lin Y (2003) Solubilization of carbon nanotubes by nafion toward the preparation of amperometric biosensors. J Am Chem Soc 125(9):2408-2409. doi: $10.1021 / \mathrm{ja} 028951 \mathrm{v}$

Wang Z, Yu X, Pan B, Xing B (2009) Norfloxacin sorption and its thermodynamics on surface-modified carbon nanotubes. Environ Sci Technol 44(3):978-984. doi:10.1021/es902775u

Yan Y, Zhang M, Gong K, Su L, Guo Z, Mao L (2005) Adsorption of methylene blue dye onto carbon nanotubes: a route to an electrochemically functional nanostructure and its layer-by-layer assembled nanocomposite. Chem Mater 17(13):3457-3463. doi:10.1021/cm0504182

Yan XM, Shi BY, Lu JJ, Feng CH, Wang DS, Tang HX (2008) Adsorption and desorption of atrazine on carbon nanotubes. J Colloid Interface Sci 321(1):30-38. doi:10.1016/j. jcis.2008.01.047

Yang K, Xing B (2010) Adsorption of organic compounds by carbon nanomaterials in aqueous phase: Polanyi theory and its application. Chem Rev 110(10):5989-6008. doi:10. $1021 / \mathrm{cr} 100059 \mathrm{~s}$

Yao Y, Xu F, Chen M, Xu Z, Zhu Z (2010) Adsorption behavior of methylene blue on carbon nanotubes. Bioresour Technol 101(9):3040-3046. doi:10.1016/j.biortech.2009.12.042

Zarudnev ES, Plokhotnichenko AM, Leontiev VS, Levitsky IA, Karachevtsev VA (2012) Unusual aggregation of poly(rC)wrapped carbon nanotubes in aqueous suspension induced by cationic porphyrin. J Mater Chem 22(21):10795-10804. doi:10.1039/c2jm30645j 